\title{
PARTICIPAÇÃO E INFLUÊNCIA POLÍTICA NO CONSELHO MUNICIPAL DE SAÚDE DE CURITIBA
}

\author{
Mário Fuks
}

\begin{abstract}
RESUMO
Neste artigo, analisamos o processo decisório do Conselho Municipal de Saúde de Curitiba (CMSC), tendo como foco a distribuição da influência política entre os diversos segmentos. Após explorar o modelo fundado na posse de recursos, concluímos que a distribuição da influência política no CMSC não pode ser atribuída, exclusivamente, à posse diferenciada de recursos convencionais. Propomos, então, uma versão ampliada desse modelo, incluindo recursos não-convencionais. Além disso, sugerimos que os fatores que configuram os contextos nos quais os conselhos se inserem contribuem para a formação de distintos padrões de ação $e$ interação e ajudam a explicar porque nem sempre os recursos se traduzem em influência política.
\end{abstract}

PALAVRAS-CHAVE: participação política; influência política; Conselho Municipal de Saúde de Curitiba; recursos.

\section{INTRODUÇÃO}

Embora os conselhos gestores de políticas sociais tenham como um de seus principais objetivos promover a participação da sociedade civil na condução da “coisa pública”, essa participação não segue como decorrência natural do funcionamento dos conselhos. A mera institucionalização dessas arenas, embora tenha valor em si, não é condição suficiente para que a participação política ocorra em "sintonia fina" com o espírito da Constituição Federal de 1988, referente à organização da experiência democrática, com os ideais dos atores envolvidos ou mesmo com os valores dos pesquisadores.

Com o objetivo de combater uma posição apriorística em relação à participação política em instituições dessa natureza, este artigo pretende estudar o comportamento político dos diversos setores no processo decisório do Conselho Municipal de Saúde de Curitiba (CMSC). A questão de fundo que orientará a análise refere-se à concentração ou dispersão da participação e da influência política. Mais especificamente, interessa-nos saber se e em que medida determinados atores controlam o processo decisório no Conselho Municipal de Saúde de Curitiba.

Mas não nos interessa apenas verificar a existência de setores mais influentes no CMSC. Nossa principal finalidade é compreender a distribuição da participação e da influência política no
CMSC. Com esse propósito, exploramos as possibilidades explicativas e os limites do modelo que associa a influência política à posse de recursos por parte dos indivíduos e grupos que atuam em uma determinada arena política.

A primeira parte deste artigo é dedicada à apresentação dos dados e à análise da distribuição da participação e da influência política no CMSC. Em seguida, apresentamos uma explicação para a distribuição da influência política baseada na posse diferenciada de recursos, incluindo recursos nãoconvencionais no modelo. Na última seção, indicamos aspectos não considerados pela abordagem centrada na posse de recursos que contribuem para uma compreensão mais satisfatória do exercício da influência política no CMSC.

\section{DISTRIBUIÇÃO DA PARTICIPAÇÃO E DA INFLUÊNCIA POLÍTICA}

Examinaremos, neste trabalho, uma década de funcionamento do Conselho Municipal de Saúde de Curitiba, referente a cinco gestões do Conselho ${ }^{1}$, desde a sua criação até o ano de 2001. Para realizar tal tarefa, precisamos, antes, identificar

\footnotetext{
1 Neste trabalho apresentaremos resultados parciais da pesquisa “Democracia e políticas sociais no Paraná”. Essa pesquisa foi financiada pelo Conselho Nacional de Desenvolvimento Científico e Tecnológico (CNPq), coordenada pelo Professor Mário Fuks e desenvolvida pelo Núcleo de pesquisa "Democracia e instituições políticas paranaenses”,
} 
os segmentos que compõem o Conselho. Desde a sua segunda gestão (1993-1995), o CMSC é composto por 32 membros, obedecendo a seguinte distribuição ${ }^{2}$ : usuários (16), trabalhadores do setor (8), prestadores de serviço (4) e gestores (4).

A influência política dos atores será aqui avaliada a partir de um critério quantitativo: o peso de sua participação nos debates e decisões tomadas pelo Conselho ${ }^{3}$. Certamente, o conceito de "influência política" associado a esse critério é limitado mas entendemos que, em alguma medida, a influência vem acompanhada de participação política e que essa pode ser examinada a partir de um repertório de ações, tais como o "uso da palavra" e o "encaminhamento de propostas" para deliberação $0^{4}$.

da Universidade Federal do Paraná (UFPR). A pesquisa contou com a consultoria na área de estatística e processamento de dados do professor Malco Camargos. Além de incluir um estudo mais abrangente do Conselho Municipal de Saúde de Curitiba (1991-2001), a pesquisa também investigou o Conselho Municipal de Assistência Social de Curitiba (Cmasc), o Conselho Municipal dos Direitos da Criança e Adolescente de Curitiba (Comtiba), o Conselho Municipal do Emprego e Relações de Trabalho de Curitiba (Cmert), o Conselho de Saúde da Região Sul de Londrina (Consul), o Conselho de Saúde de Londrina e o Conselho Estadual da Assistência Social do Paraná.

2 O segmento "gestor” é constituído pelos representantes do governo no conselho. Além do próprio Secretário Municipal de Saúde, representantes estatais das áreas técnicas da saúde e de outras secretarias de apoio (ex: representantes da Secretaria de Finanças) constituem o segmento "gestor". O segmento "prestador de serviço" é representado tanto pelos próprios prestadores privados e públicos (ex: Hospital das Clínicas da UFPR) de serviço na área da saúde como por categorias profissionais que representam esse setor (ex: Conselho Regional de Odontologia do Paraná). O segmento "trabalhador do setor", que representa os trabalhadores que atuam na área de saúde, e o segmento "usuário”, representando os usuários do sistema de saúde, são os segmentos que têm, por natureza, uma representação coletiva (ex: sindicatos, associações de moradores, conselhos comunitários, associações de portadores de doenças).

3 A fonte utilizada para a realização da pesquisa é constituída pelo conjunto das atas de reunião do Conselho Municipal de Saúde de Curitiba, abrangendo o período de 1991 a 2001.

4 Do ponto de vista metodológico, examinar-como fizemos em nossa pesquisa - a influência política por meio desse "repertório de ações informais” justifica-se como uma forma de lidar com as dificuldades inerentes ao estudo de arenas caracterizadas por “baixa institucionalidade”, em que predominam procedimentos informais e, principalmente, tipos de deliberação que não assumem o caráter de uma norma jurídica.
Em nosso estudo, essa participação foi investigada em três dimensões, correspondendo aos três momentos do processo decisório ${ }^{5}: 1$ ) iniciar e dar continuidade ao debate a respeito de certo tema de pauta; 2) encaminhar proposta para deliberação; 3) aprovar ou não a proposta.

Ao longo dos seus primeiro dez anos de vida, o Conselho Municipal de Saúde de Curitiba atuou como um fórum permanente de debate na área de saúde (Tabela 1). O CMSC tem reservado parte considerável de suas reuniões para o debate a respeito dos temas de sua agenda, especialmente em comparação com outros conselhos gestores de políticas públicas que atuam em Curitiba6.

TABELA 1 - EXISTÊNCIA DE DEBATE

\begin{tabular}{|l|c|c|}
\hline & $\boldsymbol{N}$. & $\%$ \\
\hline Sim & 325 & 45,2 \\
\hline Não & 394 & 54,8 \\
\hline Total & 719 & 100,0 \\
\hline
\end{tabular}

FONTE: Núcleo de pesquisa "Democracia e instituições políticas paranaenses" (s/d).

Embora esses dados sejam relevantes para a compreensão do tipo de democracia que prevalece no $\mathrm{CMSC}^{7}$, interessa-nos aqui saber como a participação no debate é distribuída entre os membros do Conselho. As atas de suas reuniões indicam que a participação mais expressiva no CMSC não é protagonizada pelos seus próprios membros (Tabela 2). Ao longo de suas cinco primeiras gestões, parte significativa dos debates ocorridos

5 Ao limitarmos o campo de nossa investigação ao processo decisório no âmbito das reuniões do CMSC, ficaram fora do alcance de nossa investigação vários aspectos da ação política dos grupos, entre os quais se destacam dois: 1) as estratégias de definição e "negação" de agenda (COBB \& ROSS, 1997) e 2) a ação política no sistema mais amplo de arenas públicas (HILGARTNER \& BOSK, 1988) da área de saúde. Embora não tenham sido objeto de análise empírica, esses aspectos da influência política foram considerados entre as possíveis explicações para os resultados de nossa análise.

6 No Conselho Municipal dos Direitos da Criança e Adolescente de Curitiba (Comtiba), por exemplo, o debate corresponde a apenas $12,1 \%$ dos 653 pontos de pauta referentes ao período 1997-2001.

7 Especialmente para avaliarmos em que medida o CMSC pauta-se por um modelo deliberativo de democracia. 
nessa instituição foi iniciada por atores externos ao próprio Conselho. Nem mesmo a soma de todas as intervenções iniciais por parte dos segmentos da sociedade civil que participam do órgão consegue superar aquela proveniente de "atores externos"

TABELA 2 - ATOR QUE INICIA O DEBATE, POR SEGMENTO ${ }^{9}$

\begin{tabular}{|l|c|c|}
\hline \multicolumn{1}{|c|}{ ATORES } & $\boldsymbol{N .}$ & \% \\
\hline Gestor & 165 & 33,5 \\
\hline Prestador & 12 & 2,4 \\
\hline Trabalhador & 51 & 10,4 \\
\hline Usuário & 93 & 18,9 \\
\hline Ator externo & 171 & 34,8 \\
\hline Total & 249 & 100,0 \\
\hline
\end{tabular}

FONTE: Núcleo de pesquisa "Democracia e instituições políticas paranaenses" (s/d).

Uma análise superficial do processo decisório do CMSC revelaria, então, que se trata de uma instituição altamente permeável à participação da população. Esse Conselho pareceria ser um espaço de ampla mobilização social e de participação política ampliada. Mas, na verdade, esses números apenas indicam, no que diz respeito ao "ator externo", a participação de atores estatais que atuam no CMSC como "apoio técnico" (Tabela 3), apresentando programas governamentais, oferecendo esclarecimentos, transmitindo informações do governo e emitindo pareceres a respeito de assuntos de sua competência (como, por exemplo, a prestação de contas do Fundo Municipal de Saúde) ${ }^{10}$.

8 Essa categoria inclui os seguintes tipos de atores: apoio técnico estatal; apoio técnico não-estatal e "visitantes". Chamamos de "visitantes” indivíduos e organizações da sociedade civil que comparecem a uma reunião do CMSC sem serem membros do Conselho.

9 A fonte utilizada para a coleta dos dados referentes ao processo decisório foram as atas das reuniões do CMSC.É importante observar que, em parte significativa das deliberações, não foi possível identificar o ator, pois não constava nem o seu nome nem o da organização que ele representava. Decidimos, neste trabalho, apresentar apenas os dados referentes aos casos em que houve a identificação do ator.

10 Freqüentemente, quadros técnicos da Administração participam das comissões internas do Conselho e, nessa condição, fazem uso da palavra.
TABELA 3 - ATOR QUE INICIA O DEBATE, POR CATEGORIA

\begin{tabular}{|l|c|c|}
\hline & N. & \% \\
\hline Mesa Diretora & 130 & 24,8 \\
\hline Membro de comissão & 86 & 16,4 \\
\hline Membro do Conselho & 150 & 28,6 \\
\hline Apoio técnico estatal & 132 & 25,1 \\
\hline Visitantes & 27 & 5,2 \\
\hline Total & 525 & 100,0 \\
\hline
\end{tabular}

FONTE: Núcleo de pesquisa "Democracia e instituições políticas paranaenses" (s/d).

O que se pode concluir aqui é que, embora em minoria no CMSC, os atores governamentais controlam a iniciativa ${ }^{11}$ no campo do debate, introduzindo os assuntos em pauta em, ao menos ${ }^{12}$, $58,6 \%$ dos casos (o segmento gestor, em 33,5\%, e o apoio técnico estatal, em $25,1 \%$ ). Isso ocorre, em parte, devido ao papel central que o gestor tem ocupado na Mesa Diretora, na permanente condição de Presidente do CMSC. De outro lado, isso também revela o peso do conhecimento técnico na dinâmica do Conselho, o que confere a assessores técnicos papel decisivo na disseminação da informação a respeito das ações e programas governamentais, assim como dos aspectos técnicos envolvidos em assuntos específicos de interesse do Conselho.

O segmento do conselho que representa o gestor dispõe, portanto, de um recurso escasso e, por isso mesmo, importantíssimo: a informação. Esse acesso privilegiado à informação, em certos aspectos tendendo ao monopólio, constitui um importante recurso de poder, considerando que essa informação pode ser sonegada, divulgada parcialmente ou mesmo manipulada em função dos interesses de quem dela dispõe. Por outro lado, devemos levar em conta que, em relação a esse

11 É importante observar que "iniciar o debate” não é a mesma coisa que "definir a agenda”. Em alguns casos, quem toma a iniciativa de abrir o debate é o mesmo ator que o introduziu na agenda, mas, com freqüência, cabe à Mesa Diretora introduzir o tema em pauta.

12 O número de iniciativas do "ator externo” (171) é maior do que a soma das iniciativas do "visitante", "movimento social” e "apoio técnico estatal” (159). Isso ocorre em virtude do fato de que, com certa freqüência, não foi possível identificar, nas atas das reuniões, a categoria do ator que iniciava o debate. 
aspecto, o CMSC constitui-se como um importante canal de veiculação não apenas de saber técnico, qualificando os seus membros, mas também de circulação pública de informações anteriormente restritas à esfera governamental ${ }^{13}$.

Além de identificar quem iniciou a discussão sobre os temas em pauta, os dados coletados permitem identificar o ator que, dando seqüência ao assunto, estabelece, de fato, o debate ${ }^{14}$. Nota-se (Tabela 4) a presença marcante do usuário, sendo ele o responsável por 39,3\% do total das intervenções. Por outro lado, impressiona a passividade do segmento dos prestadores de serviço que, mesmo sendo membro do conselho, tem menor participação no CMSC do que o "visitante"15. Torna-se claro, então, que a dinâmica do Conselho obedece a seguinte lógica: os atores estatais iniciam o debate e, em seguida, entram no debate os usuários e, com menor freqüência, os trabalhadores.

TABELA 4 - INTERLOCUTOR, POR SEGMENTO

\begin{tabular}{|l|c|c|}
\hline SEGMENTO & $\boldsymbol{N .}$ & $\%$ \\
\hline Gestor & 50 & 19,1 \\
\hline Prestador & 19 & 7,3 \\
\hline Trabalhador & 51 & 19,5 \\
\hline Usuário & 103 & 39,3 \\
\hline Ator externo & 39 & 14,8 \\
\hline Total & 262 & 100,0 \\
\hline
\end{tabular}

FONTE: Núcleo de pesquisa "Democracia e instituições políticas paranaenses" (s/d).

\footnotetext{
13 Mesmo porque o Conselho pode solicitar ao governo a prestação de informações a respeito de ações e programas governamentais na área de saúde.
}

14 Tecnicamente o procedimento adotado foi o de identificar o segundo ator a fazer uso da palavra, dando prosseguimento ao tema em pauta.. Não foram consideradas as intervenções de ordem "formal”, tais como o pedido de esclarecimento, a solicitação de adiamento da discussão, encaminhamentos, questões de ordem, informes e outras formalidades. Pode-se questionar a importância do segundo ator a fazer uso da palavra, pois há relação necessária entre a ordem da fala e o grau de importância da intervenção no debate. Se seguíssemos essa linha de raciocínio, teríamos apenas uma alternativa: registrar, na planilha, todas as intervenções ocorridas nos dez anos da gestão em estudo. Se, de um lado, a nossa escolha parece um tanto quanto arbitrária, de outro lado, acreditamos que, conforme o leitor terá oportunidade de avaliar, a análise revelou a utilidade de tal procedimento, apontando certos padrões de intervenção dos segmentos do CMSC.
Quando agregamos os dados referentes à participação em debate, fica evidente quais são os segmentos mais ativos nas reuniões do CMSC (Tabela 5). Há, praticamente, um empate entre três segmentos: o gestor, o usuário e o ator externo ${ }^{16}$. Chama a atenção o fato de que o "ator externo" tem maior participação, no debate, do que qualquer um dos segmentos que representam a sociedade civil no CMSC. Conforme já observado, isso ocorre, em grande medida, devido à participação ativa dos quadros técnicos do governo municipal nos debates do Conselho.

TABELA 5 - PARTICIPAÇÃO NO DEBATE, POR SEGMENTO

\begin{tabular}{|l|c|c|}
\hline SEGMENTO & N. & \% \\
\hline Gestor & 215 & 28,5 \\
\hline Prestador & 31 & 4,1 \\
\hline Trabalhador & 102 & 13,5 \\
\hline Usuário & 196 & 26,0 \\
\hline Ator externo & 210 & 27,9 \\
\hline Total & 754 & 100,0 \\
\hline
\end{tabular}

FONTE: Núcleo de pesquisa "Democracia e instituições políticas paranaenses" (s/d).

Se comparado com os demais conselhos estudados, o CMSC pode ser considerado não apenas uma arena de debate, mas de controvérsia pública. Conforme já observado (Tabela 1), praticamente, a metade (46\% dos casos) dos assuntos da agenda do conselho gerou debate ${ }^{17}$ e aproximadamente um em cada dez assuntos em pauta

15 Nesse caso, o "visitante” é o responsável pela maior parte das intervenções do "ator externo". O apoio técnico estatal concentra a sua participação na apresentação dos assuntos de pauta.

16 Especialmente se considerarmos que, na primeira gestão do Conselho, devido ao seu caráter excepcional, os gestores atuaram de maneira bem mais incisiva do que nas gestões posteriores. Em certas gestões, como a de 19992001, a participação dos usuários no debate foi superior à do gestor.

17 Devemos considerar a natureza "técnica” de diversos pontos de pauta (como, por exemplo, a apresentação e esclarecimento a respeito de programas e de projetos governamentais em andamento etc.), além de que certos assuntos entram, de imediato, em votação, como, por exemplo, a escolha de representantes do Conselho para participar de algum evento. 
$(12,8 \%)$ suscitou contestação, conforme definida por nossa metodologia ${ }^{18}$. As contestações são protagonizadas pelos usuários (42,2\% dos casos). O gestor $(17,2 \%)$ e o trabalhador no setor $(21,9 \%)$ atuam como coadjuvantes, seguidos, logo atrás, pelo ator externo $(10,9 \%$, sendo, nesse caso, todos visitantes) e pelo prestador (7,8\%).

Sendo o usuário o segmento da sociedade civil que mais participa do debate e que mais gera a controvérsia pública, podemos sugerir a presença da seguinte dinâmica na reunião do conselho: 1) fazendo uso de recursos cognitivos e das prerrogativas dos cargos que ocupam, os atores estatais lideram as discussões no CMSC, apresentando os assuntos da pauta, esclarecendo questões de ordem técnica, divulgando informações governamentais - enfim, introduzindo o debate; 2) os usuários apresentam-se como interlocutores e, em certas circunstâncias, contrapõem (secundados pelos trabalhadores) argumentos aos dos gestores. Portanto, o usuário e o gestor são ativos não apenas no sentido de participarem do debate, mas também porque são os que mais conferem a esse debate a qualidade de confrontação de idéias.

A distribuição da participação dos diferentes segmentos ao longo do processo decisório do CMSC tende a ser estável. O prestador mantémse, praticamente, invisível durante todo o processo, tanto no debate como no encaminhamento de propostas para deliberação. $\mathrm{O}$ trabalhador e, especialmente, o usuário têm maior presença, contrapondo-se às intervenções iniciais do gestor e competindo com ele no campo da apresentação de propostas a serem votadas. Como se pode observar, o gestor encaminha para a votação quase o mesmo número de propostas que a soma das propostas encaminhadas pelos demais segmentos que têm assento no Conselho (Tabela 6). Embora esse número não seja tão expressivo quanto o da iniciativa no campo do debate, ele consolida a liderança do gestor no processo decisório do órgão. Da mesma forma, os dados referentes ao encaminhamento de propostas deixam claro que o usuário é o segmento da sociedade civil organizada mais ativo nas reuniões do CMSC.

\footnotetext{
18 A presença de “contestação” foi registrada sempre quando a intervenção do segundo ator opôs-se explicitamente à do que iniciou o debate.
}

TABELA 6 - PROPOSTAS APRESENTADAS, POR SEGMENTO

\begin{tabular}{|l|c|c|}
\hline SEGMENTO & N. & \% \\
\hline Gestor & 108 & 39,7 \\
\hline Prestador & 7 & 2,5 \\
\hline Trabalhador & 43 & 15,8 \\
\hline Usuário & 79 & 29,1 \\
\hline Ator externo & 35 & 12,9 \\
\hline Total & 272 & 100,0 \\
\hline
\end{tabular}

FONTE: Núcleo de pesquisa "Democracia e instituições políticas paranaenses" (s/d).

O conjunto dos dados analisado permite-nos concluir que: 1) o gestor tem sido, ao longo da primeira década de existência do CMSC, o segmento com maior volume de ação no CMSC; 2) embora não atue como membro do Conselho (portanto, sem direto a voto) o quadro técnico do governo tem reforçado a predominância dos atores estatais no CMSC; 3) entre os conselheiros da sociedade civil, o usuário tem-se destacado como segmento mais atuante, tanto no debate como no encaminhamento de propostas para deliberação, sendo o principal responsável pelo estabelecendo uma relação de equilíbrio entre os segmentos da sociedade civil e os setores do Conselho que atuam em nome da administração pública e 4) a presença do prestador de serviço no Conselho é, praticamente, invisível.

Quando consideramos apenas as deliberações em que houve controvérsia, seguidas de encaminhamento de mais de uma proposta para votação, o gestor permanece sendo o segmento com maior iniciativa no encaminhamento da proposta original para votação (21 propostas), seguido pelo usuário (16 propostas). Nesse contexto, o trabalhador torna-se mais ativo, aproximando-se do usuário (14 propostas). Por outro, lado, o usuário destaca-se enquanto formulador de proposta alternativa (19 propostas), superando o gestor (11 propostas). Considerando a totalidade das propostas encaminhadas em contexto de controvérsia, o usuário (35 propostas) supera o gestor (32 propostas). Percebe-se, então, que o conflito político no âmbito do CMSC gera um cenário de equilíbrio, tendo como novidade uma presença maior do trabalhador e o papel contestador do usuário. Considerando, ainda, que o usuário apresentou um número ligeiramente superior (11) de propostas de resolução ao CMSC do que o gestor (9 pro- 
postas), a idéia de que há um relativo equilíbrio de influência política no interior dessa arena fica reforçada ${ }^{19}$. Esse equilíbrio resulta, de um lado, das iniciativas incessantes do gestor no campo do debate e da deliberação, contando ainda com o auxílio do corpo técnico governamental, e, de outro, da ação constante do usuário em todas as etapas do processo decisório, muitas vezes em articulação com setores do segmento dos trabalhadores na área de saúde.

$\mathrm{O}$ que, no entanto, impede-se de realizar uma avaliação conclusiva a respeito da influência de cada segmento no processo decisório do CMSC é o fato de que, praticamente, todas as propostas encaminhadas foram aprovadas ${ }^{20}$. Mas por que o CMSC teria como regra aprovar as propostas apreciadas em suas reuniões? Podemos, aqui, apenas especular, supondo, por exemplo, que o CMSC tende a estruturar a sua agenda com temas e propostas que estejam em sintonia com os interesses da maioria de seus membros, excluindo de sua agenda os temas não consensuais. Podemos igualmente supor que os determinados setores do CMSC consigam "impor”, na agenda do órgão os temas que atendem apenas aos seus próprios interesses. Em ambos os casos, a influência é exercida no processo de constituição de um "filtro", que define quais as questões sujeitas a debate e quais serão excluídas do processo decisório 21 (COBB \& ROSS, 1997).

Dessa forma, a análise do processo decisório do CMSC indica que a explicação baseada, exclusivamente, nos dados fornecidos pela dinâmica interna do processo decisório é insuficiente para entendermos os processos por meio dos quais a influência política é exercida. Essa questão será tratada na próxima seção, na qual buscaremos explicar a distribuição da participação e da influência política no interior do CMSC.

19 Já a distribuição dos temas submetidos à deliberação não contribui muito para qualificar a influência política dentro do CMSC, especialmente devido ao fato de que essa distribuição tende a ser homogênea.

20 De um total de 597 deliberações, 577 (96,6\%) foram aprovadas.

21 Sem o exame do processo de formulação da agenda, não podemos avaliar se e em que medida os interesses de cada segmento foram atendidos mediante a inclusão e a exclusão de determinados assuntos na pauta de deliberação do Conselho.
III. CONDIÇÕES FAVORÁVEIS À AÇÃO POLÍTICA: RECURSOS CONVENCIONAIS E RECURSOS NÃO-CONVENCIONAIS

A participação política não pode ser devidamente entendida sem levarmos em consideração que ela ocorre em um contexto em que estão presentes os interesses e as ações de diversos atores. Em outras palavras, a participação assume sempre a forma de interação política.

Nesse contexto, a influência de cada ator, entendida como eficácia da ação em termos da consecução de seus objetivos políticos, está, em alguma medida, associada aos recursos de que ele dispõe. Os recursos são meios disponíveis para indivíduos ou para as organizações que aumentam a sua capacidade de ação e de influência política. Em nossa pesquisa, os agentes no interior dos conselhos foram identificados como portadores de dois tipos de recursos: 1) os "recursos individuais”, referentes ao perfil sócio-econômico e educacional dos conselheiros, e 2) os "recursos coletivos”, que são de natureza organizacional (financeiros, materiais e humanos) ou política, pertencentes às entidades representadas no CMSC.

Como observação preliminar, no Conselho Municipal de Saúde de Curitiba, nenhum segmento controla em regime de monopólio qualquer um dos recursos analisados. Além disso, se é verdade que, no CMSC, há desigualdades na distribuição de recursos, essas desigualdades são dispersas e não cumulativas (FUKS, PERISSINOTTO \& RIBEIRO, 2003).

Em relação aos recursos individuais ${ }^{22}$, confirma-se o esperado: a desvantagem dos usuários no que se refere à renda e à escolaridade. No caso da renda, $60 \%$ dos usuários ganham até 10 salári-

22 Os dados apresentados a seguir, referentes à posse de recursos, foram coletados mediante entrevista com 30 conselheiros que participaram da gestão 1999-2001 do Conselho Municipal de Saúde de Curitiba. Do conjunto de conselheiros dessa gestão, apenas dois conselheiros não foram localizados e, portanto, não foram entrevistados. A distribuição das entrevistas por segmento foi a seguinte: quinze usuários, sete trabalhadores, quatro prestadores de serviço e quatro gestores. A predominância do segmento "usuário" explica-se pelo fato de os conselhos de saúde serem "paritários", sendo 50\% de seus membros representantes dos usuários do sistema de saúde. 
os mínimos, enquanto em relação aos demais segmentos o percentual não ultrapassa $30 \%$.

Em relação à escolaridade, 60\% dos usuários têm, no máximo, Ensino Médio completo. Esse número cai para $28,6 \%$, no caso dos trabalhadores, sendo que todos os prestadores e gestores já ingressaram no Ensino Superior.

TABELA 7 - NÍVEL DE ESCOLARIDADE, POR SEGMENTO

\begin{tabular}{|c|c|c|c|c|c|c|}
\hline $\begin{array}{l}\text { NÍVEL DE } \\
\text { ESCOLARIDADE }\end{array}$ & & USUÁRIO & $\begin{array}{l}\text { TRABALHADOR } \\
\text { DO SETOR }\end{array}$ & $\begin{array}{l}\text { PRESTADOR } \\
\text { DE SERVIÇO }\end{array}$ & GESTOR & TOTAL \\
\hline \multirow{2}{*}{$\begin{array}{l}\text { Ensino Fundamental } \\
\text { incompleto }\end{array}$} & $\mathrm{N}$ & 1 & & & & 1 \\
\hline & $\%$ & 6,7 & & & & 3,3 \\
\hline \multirow{2}{*}{$\begin{array}{l}\text { Ensino Fundamental } \\
\text { completo }\end{array}$} & $\mathrm{N}$ & 2 & 1 & & & 3 \\
\hline & $\%$ & 13,3 & 14,3 & & & 10,0 \\
\hline \multirow[t]{2}{*}{ Ensino Médio completo } & $\mathrm{N}$ & 6 & 1 & & & 7 \\
\hline & $\%$ & 40,0 & 14,3 & & & 23,3 \\
\hline \multirow{2}{*}{$\begin{array}{l}\text { Ensino Superior } \\
\text { incompleto }\end{array}$} & $\mathrm{N}$ & 2 & & & & 2 \\
\hline & $\%$ & 13,3 & & & & 6,7 \\
\hline \multirow{2}{*}{$\begin{array}{l}\text { Ensino Superior } \\
\text { completo }\end{array}$} & $\mathrm{N}$ & 1 & 1 & & & 4 \\
\hline & $\%$ & 6,7 & 14,3 & & & 13,3 \\
\hline \multirow{2}{*}{$\begin{array}{l}\text { Pós-graduação } \\
\text { incompleta }\end{array}$} & $\mathrm{N}$ & 1 & 2 & 1 & & 4 \\
\hline & $\%$ & 6,7 & 28,6 & 25,0 & & 13,3 \\
\hline \multirow[t]{2}{*}{ Pós-graduação completa } & $\mathrm{N}$ & 2 & 2 & 2 & 3 & 9 \\
\hline & $\%$ & 13,3 & 28,6 & 50,0 & 75,0 & 30,0 \\
\hline \multirow[t]{2}{*}{ Total } & $\mathrm{N}$ & 15 & 7 & 4 & 4 & 30 \\
\hline & $\%$ & 100,0 & 100,0 & 100,0 & 100,0 & 100,0 \\
\hline
\end{tabular}

FONTE: Núcleo de pesquisa "Democracia e instituições políticas paranaenses" (s/d).

Não apenas individualmente os usuários contam com menos recursos que os demais segmentos: sua inferioridade também pode ser identificada em relação às organizações representadas nos conselhos. Enquanto 91,7\% das organizações dos usuários têm um orçamento anual inferior a $\mathrm{R} \$$ 100 mil, 50\% das entidades dos trabalhadores e $75 \%$ dos prestadores têm orçamentos anuais superiores a R\$ 100 mil. Além disso, grande parte das associações dos trabalhadores $(71,4 \%)$ e todas as organizações dos prestadores de serviço possuem funcionários, ao contrário do que ocorre em relação aos usuários (13,3\%). A mesma tendência ocorre em relação aos demais recursos organizacionais: computador, sede, telefone, fax, vídeo e veículo de comunicação.

Os dados apresentados não poderiam ser mais persuasivos no sentido de apontar uma clara hierarquia entre os segmentos quanto à posse de recursos. Em primeiro lugar, com destaque, situa- se o gestor ${ }^{23}$. O segmento da sociedade civil que dispõe de maior volume de recursos é o prestador, seguido pelo trabalhador. A fragilidade do usuário em relação à posse de recursos tradicionais, tanto individuais como coletivos, coloca-o em condição inequívoca de desvantagem em relação aos demais segmentos.

Uma análise preliminar desses dados indica que a distribuição da influência política no Conselho deve seguir a seguinte ordem: gestor, prestador, trabalhador e usuário. Quaisquer que sejam os

23 Conforme se pode observar, não foram coletadas informações sobre os recursos coletivos do gestor. Isso porque a "organização" (o Estado) a que pertence o gestor é de natureza diversa daquela a que pertencem os segmentos da sociedade civil. Em comparação com os demais segmentos, o gestor encontra-se em vantagem absoluta em termos dos recursos coletivos de que dispõe. 
critérios para definirmos o peso relativo de cada tipo de recurso, a hierarquia estabelecida acima evidencia os limites de uma explicação da influência política baseada exclusivamente na posse de recursos.

A participação dos gestores no Conselho Municipal de Saúde de Curitiba é adequadamente explicada em termos dos recursos de que esse segmento dispõe. O mesmo pode ser dito em relação aos trabalhadores. Mais difícil é explicar a participação dos demais segmentos a partir da mesma lógica. No caso do CMSC, o "ativismo" dos usuários e, especialmente, a passividade dos prestadores não podem ser totalmente explicados pela posse de recursos. A realidade que nos revela o processo decisório do Conselho em seus primeiros dez anos 24 estaria mais de acordo com o modelo que supõe haver uma simetria entre a participação política e a posse de recursos se houvesse uma inversão entre as posições do prestador e a do usuário na distribuição de recursos.

Como, então, explicar o ativismo do usuário no CMSC? Um dos motivos pelos quais a explicação fundada na posse de recursos convencionais é limitada e, no caso da análise em curso, é incapaz de dar conta dos fenômenos investigados é a desconsideração de, ao menos, três outras dimensões igualmente importantes para a ação política: 1) a primeira, mais subjetiva, diz respeito à propensão dos conselheiros para o engajamento político $^{25}$ (medida em termos do interesse cognitivo e emocional - por política e da competência política subjetiva); 2) a segunda, mais prática, assume a forma de engajamento eleitoral, associativismo e filiação partidária; 3) a terceira também de natureza prática - refere-se a atributos coletivos de caráter mais complexo do que os recursos organizacionais, como a rede de apoio político e a ação reiterada junto às instituições estatais.

\footnotetext{
24 É importante observar que os dados de que dispomos em relação aos recursos cobrem apenas uma gestão do Conselho. Supomos, aqui, uma relativa estabilidade, ao longo do tempo, em termos dos recursos de que cada segmento dispõe.

25 A motivação (ou sua ausência) para participação tem sido considerada (MARSCHALL, 2000) como um dos aspectos que propiciam (ou impedem) a participação política.
}

Devemos, portanto, considerar não apenas os recursos convencionais, como renda e escolaridade, no caso do indivíduo, ou recursos materiais ou humanos, no caso das organizações. Recursos de natureza menos tangível, mas, nem por isso, menos eficazes, indicando, por exemplo, certa disposição para a participação política, são especialmente relevantes e têm sido levados em consideração em estudos de cultura política (SCHLOZMAN, VERBA \& BRADY, 1999; SKOCPOL \& FIORINA, 1999; FUKS, PERISSINOTTO \& RIBEIRO, 2003). O pertencimento a associações da sociedade civil e a filiação partidária certamente estão associados à presença de certa motivação para a ação política além das habilidades políticas específicas adquiridas nessas experiências -, constituindo-se, portanto, como um importante indicador da presença dessa condição subjetiva.

Os usuários superam, de longe, os demais segmentos quando se trata da filiação partidária. Apenas 14,3\% dos usuários não são filiados a nenhum partido, em comparação com os $71,4 \%$ dos trabalhadores e com os $50 \%$ dos prestadores e dos gestores. A mesma tendência manifesta-se em relação à preferência partidária.

Já a filiação a associações da sociedade civil é bem distribuída entre os segmentos. Apenas dois conselheiros entrevistados não têm qualquer vínculo associativo. Embora os usuários e trabalhadores tenham, com maior freqüência, o hábito de associar-se, o comportamento associativo é compartilhado por todos os segmentos do CMSC $^{26}$. A prática associativa dos segmentos é menos uniforme no que diz respeito ao tipo de associação. Os trabalhadores filiam-se, predominantemente, a associações de classe $(71,4)$ e sindicatos (53,3\%). Essa mesma tendência ocorre, em menor grau, com os prestadores e os gestores. A prática associativa dos usuários concentra-se nos movimentos religiosos (66,7\%) e nas associações de bairros (53,3\%).

A filiação do indivíduo a uma determinada associação ou a um partido político pode assumir a forma de uma relação passiva ou mesmo puramente formal. Uma forma de compensar a limita-

26 Especialmente considerando que o pertencimento a uma associação é requisito para participar do CMSC apenas no caso dos usuários e dos trabalhadores. 
ção desses vínculos quanto à sua capacidade de revelar a intensidade da motivação para agir politicamente é por meio da informação a respeito do envolvimento efetivo dos conselheiros em atividades políticas.

Uma das principais atividades dessa natureza é o engajamento eleitoral. Em relação a esse tipo de atividade político-partidária, chama atenção a força (ativismo) dos usuários e a fraqueza (apatia) dos prestadores ${ }^{27}$ (Tabela 8). Em nenhuma atividade eleitoral durante a campanha para a Prefeitura de Curitiba no ano 2000 a participação do usuário foi inferior a $73,3 \%{ }^{28}$. Já os prestadores não contam com a participação de mais $25 \%$ de seus representantes nas atividades de campanha eleitoral, exceto na defesa pública do candidato de sua preferência.

TABELA 8 -ATIVIVISMO ELEITORAL, POR SEGMENTO

\begin{tabular}{|l|c|c|c|c|c|c|c|c|}
\hline \multirow{2}{*}{} & \multicolumn{2}{|c|}{ USUÁRIO } & \multicolumn{2}{c|}{$\begin{array}{c}\text { TRABALHADOR } \\
\text { DO SETOR }\end{array}$} & \multicolumn{2}{c|}{$\begin{array}{c}\text { PRESTADOR } \\
\text { DE SERVIÇO }\end{array}$} & \multicolumn{2}{c|}{ GESTOR } \\
\cline { 2 - 9 } & $\mathbf{N .}$ & $\%$ & N. & $\%$ & N. & $\%$ & N. & $\%$ \\
\hline Compareceu a comício & 13 & 86,7 & 4 & 57,1 & 1 & 25 & 4 & 100,0 \\
\hline Trabalhou gratuitamente & 11 & 73,3 & 4 & 57,1 & 1 & 25 & 3 & 75,0 \\
\hline Colou cartazes e adesivos & 11 & 73,3 & 5 & 71,4 & 1 & 25 & 4 & 100,0 \\
\hline Usou broches & 12 & 80 & 4 & 57,1 & - & - & 4 & 100,0 \\
\hline Defendeu candidato & 14 & 93,3 & 6 & 85,7 & 2 & 50 & 3 & 75 \\
\hline
\end{tabular}

FONTE: Núcleo de pesquisa "Democracia e instituições políticas paranaenses" (s/d).

Há uma relação direta entre o comportamento político dos conselheiros - expresso na forma de filiação partidária, associativa e engajamento eleitoral - e as suas orientações subjetivas, em especial no que se refere à autoconfiança do indivíduo em relação à sua capacidade de influenciar a política ${ }^{29}$. Assim, os usuários são os que, com maior freqüência, percebem-se como mais influentes no campo da política $(86,7)$. Os gestores $(75 \%)$ e os trabalhadores $(71,4 \%)$ também expressam um alto grau de competência subjetiva, ao contrário do segmento prestador (25\%), no qual prevalece a percepção de uma baixa competência política. Portanto, é exatamente aquele segmento cujo comportamento político é mais ativo que também se considera mais capaz de influenciar a política ${ }^{30}$.

\footnotetext{
27 O ativismo eleitoral dos usuários só é inferior ao dos gestores. Mas isso decorre do envolvimento político-partidário dos membros da administração pública que ocupam cargos de confiança.

28 Exceto doação de dinheiro para a campanha.

29 Ou seja, a sua competência política subjetiva (ALMOND \& VERBA, 1989).
}

30 A coerência entre as orientações subjetivas e o comportamento político no sentido aqui identificado não é um pressuposto da teoria da cultura política. A respeito desse assunto, ver Almond e Verba (1989).
Ainda no terreno das condições subjetivas, existem também os recursos cognitivos provenientes da associação entre o interesse por política e a freqüência e forma pela qual os indivíduos informam-se sobre assuntos políticos. O conhecimento e a informação política são poderosos recursos no campo da ação política, tanto porque eles orientam a ação como porque eles constituem poderosos recursos de influência política.

Ao contrário da competência política subjetiva, há uma distribuição relativamente homogênea do interesse por política entre os segmentos do CMSC. A julgar pelas informações de que já dispomos em relação ao comportamento político, podemos supor que o interesse por política revela, aqui, mais uma orientação cognitiva do que uma orientação voltada para o engajamento político ${ }^{31}$. Isso explica, por exemplo, porque o segmento "usuário", embora destaque-se em relação ao engajamento político efetivo, apresenta menos interesse por política do que os demais segmentos.

A observação acima é reforçada quando analisamos a busca de informação política (Tabela 9). Os prestadores despontam como os mais ávidos

31 Essa questão foi desenvolvida em Fuks, Perissinoto e Ribeiro (2003), tendo como referência Zaller (1992) 
por consumo de notícia política, mantendo o hábito da leitura diária de jornais e revistas. Da mesma forma, todos os prestadores costumam assistir, diariamente, ao noticiário político na televisão.
São aqueles (os usuários) que informaram ter maior engajamento político e eleitoral que realizam menor investimento no consumo de informação política pelos meios convencionais.

TABELA 9 - LEITURA SOBRE POLÍTICA EM JORNAIS E REVISTAS, POR SEGMENTO

\begin{tabular}{|l|c|c|c|c|c|c|}
\hline \multicolumn{2}{|c|}{} & USUÁRIO & $\begin{array}{c}\text { TRABALHADOR } \\
\text { DO SETOR }\end{array}$ & $\begin{array}{c}\text { PRESTADOR } \\
\text { DE SERVIÇO }\end{array}$ & GESTOR & TOTAL \\
\hline \multirow{2}{*}{ Quase todos os dias } & $N$. & 9 & 5 & 4 & 3 & 21 \\
\cline { 2 - 8 } & $\%$ & 60,0 & 71,4 & 100,0 & 75,0 & 70,0 \\
\hline \multirow{2}{*}{$\begin{array}{l}\text { Pelo menos uma vez } \\
\text { por semana }\end{array}$} & $N$. & 4 & 2 & & 1 & 7 \\
\cline { 2 - 8 } & $\%$ & 26,7 & 28,6 & & 25,0 & 23,3 \\
\hline \multirow{2}{*}{ De vez em quando } & $N$. & 1 & & & & 1 \\
\cline { 2 - 8 } & $\%$ & 6,7 & & & & 3,3 \\
\hline \multirow{2}{*}{ Nunca } & $N$. & 1 & & & & 1 \\
\cline { 2 - 8 } & $\%$ & 6,7 & & 100,0 & 100,0 & 100,0 \\
\hline \multirow{2}{*}{ Total } & $N$. & 15 & 7 & 100,0 & & \\
\cline { 2 - 8 }
\end{tabular}

FONTE: Núcleo de pesquisa "Democracia e instituições políticas paranaenses" (s/d).

Assim como os fatores individuais de ordem subjetiva, devemos também levar em consideração que certas condições objetivas tendem a aumentar a capacidade de ação dos grupos que atuam no CMSC. Essas condições estão associadas à presença de recursos coletivos não-convencionais, como a inserção dos grupos em redes de apoio político, de que podem participar atores políticos tradicionais, como os partidos e os políticos, assim como instituições (incluindo a igreja e a universidade) e diversas organizações da sociedade civil. Além disso, as organizações que participam do Conselho podem adquirir maior capacidade de participação mediante vínculos constituídos com atores estatais ou pela experiência acumulada pela ação reiterada em certas arenas, como o recurso ao poder Judiciário e a participação contínua no próprio Conselho.

A estratégia de ação política dominante das organizações que compõem o CMSC varia de acordo com o segmento em questão. Os prestadores de serviço têm uma atuação voltada para os poderes Executivo e Legislativo. Assim, os representantes dos hospitais de Curitiba (a maioria dos prestadores de serviço) encontram facilidade em estabelecer contato e encaminhar as suas demandas ao governo municipal e aos vereadores. Já os trabalhadores destacam-se quando se trata do recurso à esfera judicial, pois, tendo em vista a experiência com os litígios trabalhistas, eles adquiriram uma capacidade maior de fazerem-se presentes na arena judiciária. Os usuários, embora façam uso de outros meios, recorrem, com maior freqüência, a formas nãoinstitucionais de ação política, tais como manifestações públicas, passeatas e abaixos-assinados.

Esse quadro parece indicar que cada segmento ocupa, preferencialmente, certos nichos de ação política, possivelmente aqueles espaços mais adequados aos recursos organizacionais de que dispõe e mais permeáveis à sua atuação.

Existe uma relação estreita entre as arenas preferenciais de ação política e recursos políticos: as organizações tendem a canalizar a sua ação para aqueles atores estratégicos que fazem parte de sua rede de apoio político ou, como já indicado, para aqueles espaços institucionais mais permeáveis às suas demandas. Isso pode ser verificado em termos do tipo de apoio predominante recebido por cada segmento. Portanto, a expectativa é a de que os segmentos contem com maior apoio exatamente daqueles grupos e instituições a quem dirigem, preferencialmente, a sua ação política. 
Conforme esperado, os prestadores afirmam contar mais com o apoio dos poderes Legislativo $^{32}$ (100\%) e Executivo (50\%). Por outro lado, esse segmento indica, com pouquíssima freqüência, ter o apoio de organizações da sociedade civil. Essas organizações constituem uma importante rede de apoio político para os usuários. Os usuários identificaram as instituições religiosas $(57,1 \%)$, os sindicatos $(42,9 \%)$ e as universidades $(35,7 \%)$ como os seus principais aliados na sociedade.

Os trabalhadores concentram ainda mais a sua rede de apoio nas organizações societais. O que surpreende, nesse caso, é a pouca referência feita a sindicatos e centrais sindicais $(28,6 \%)$ como base de apoio dos trabalhadores, bem inferior ao apoio recebido pela universidade e pelas organizações não-governamentais.

Esse conjunto de condições, incluindo tanto aquelas de ordem individual e de caráter subjetivo como as que se referem às organizações e assumem uma qualidade objetiva, permite-nos elaborar uma compreensão mais abrangente do conceito de "recurso", tendo em vista os limites de uma explicação fundamentada, exclusivamente, na posse de recursos convencionais. Assim, a militância partidária, que se reflete no engajamento eleitoral, indica que a motivação para ação política pode estar compensando a fragilidade dos usuários em relação a outros recursos (p. ex.: organizacionais, cognitivos, de renda e de escolaridade). $\mathrm{O}$ apoio recebido por organizações da sociedade civil (partidos políticos, instituições religiosas, universidades) e a prática associativa (especialmente a de bairro) também parecem compensar, em parte, a menor freqüência com que ele atua junto às instituições políticas.

Por último, mas não menos importante, devemos considerar o peso da representação de cada segmento no CMSC como um dos fatores explicativos do seu comportamento político. Nesse caso, o usuário leva uma grande vantagem, pois o Conselho, sendo paritário, é constituído por 16

32 No entanto, é interessante observar que, enquanto os usuários (35,7\%) e os trabalhadores $(57,1 \%)$ afirmam ter eleito representantes no poder Legislativo, os prestadores não identificam a presença de nenhum representante do setor na Câmara dos Vereadores. representantes dos usuários e 16 representantes dos demais segmentos ${ }^{33}$.

É forçoso reconhecer que, no que se refere às condições individuais e coletivas prévias, o gestor sobressai-se como segmento que reúne as condições mais favoráveis para exercer influência política nas reuniões do CMSC. Além de dispor de recursos organizacionais ilimitados ${ }^{34}$, o gestor apresenta outras condições excepcionais: 1) ele é o único segmento com ampla disponibilidade de tempo para dedicar-se ao Conselho; 2) é possuidor, direta ou indiretamente, de recursos cognitivos altamente especializados; 3) a estrutura de funcionamento do CMSC concede ao gestor o monopólio dos dois principais recursos distribuídos no seu interior: presidir o Conselho e homologar as suas deliberações.

A posição intermediária que o trabalhador ocupa em relação à participação efetiva nas reuniões do CMSC corresponde aos meios de que dispõe em seu favor. Mais difícil é explicar a situação do prestador: a sua inércia não é congruente com a abundância de recursos de que dispõe. Conforme veremos a seguir, nesse caso, o fato de o prestador reunir condições favoráveis para a ação política não se traduz, necessariamente, na própria ação política. Isso significa que a posse de um determinado recurso não implica a sua utilização. $\mathrm{O}$ conceito central aqui é o de "disponibilidade”, sendo que se alguém dispõe de algum recurso significa que ele pode, se assim o desejar, fazer uso desse recurso. Podemos, nesse caso, supor que não haja interesse por parte dos prestadores em fazer uso de seus recursos.

\section{CONTEXTO E ESTRUTURA}

Até agora, tentamos explicar a participação política dos conselheiros em termos dos recursos de que dispõem. De certa forma, a nossa explicação ficou restrita ao modelo que associa a posse de determinados recursos à participação política dos indivíduos e grupos.

33 Sendo oito trabalhadores, quatro gestores e quatro prestadores de serviço.

34 A nossa metodologia não visou a identificar os recursos organizacionais dos gestores, considerando que eles pertencem a uma instituição cujos recursos organizacionais são tão elevados que nem sequer podem ser comparados com qualquer uma das organizações da sociedade civil que participam do Conselho. 
Inovamos apenas ao incluir um repertório de recursos não-convencionais individuais - o engajamento político e as orientações subjetivas individuais - e coletivos, em especial a rede de apoio político e os padrões dominantes de ação política.

Esse modelo ofereceu uma explicação plausível para a participação dos gestores, dos usuários e dos trabalhadores no CMSC, pois cada um desses segmentos participa do Conselho em proporção aos recursos de que dispõe. A predominância do gestor no processo decisório do órgão corresponde aos amplos recursos que se encontram à sua disposição. No caso do usuário, a pouca disponibilidade de recursos tradicionais é amplamente compensada pelas condições favoráveis em relação a recursos não-convencionais, criando, portanto, um contexto propício para o seu ativismo político nas reuniões do CMSC.

Entendemos, no entanto, que a posse de recursos não é capaz de fornecer uma explicação adequada da participação política dos prestadores de serviço no CMSC. O que o modelo fundado na posse de recursos deixa de considerar é que a mera posse de recursos não se traduz, automaticamente, em participação política. Isso explica porque o amplo estoque de recursos convencionais dos prestadores de serviço não se converte em ação política no Conselho.

Possivelmente, o principal motivo para essa discrepância entre recursos e participação é a falta de interesse dos prestadores em participar ativamente no processo decisório. Além da posse de recursos, há que se levar em consideração quais são os espaços públicos que um determinado ator elege como arenas privilegiadas de ação política. Certamente, o usuário entende ser o CMSC um espaço central de ação política, especialmente considerando a escassez de canais institucionais abertos à participação política desse segmento. $\mathrm{O}$ gestor, tanto por obrigação como por interesse, tem de atuar e conduzir o Conselho, considerando que: 1) ele é uma instância estatal aberta à participação da sociedade civil; 2) o conselho é um espaço em que o governo pode consolidar e ampliar a sua base de apoio junto à sociedade civil, tanto no sentido mais amplo da busca de legitimidade como no sentido mais específico do apoio político e eleitoral; 3) se ele não levar a sério a sua atuação no Conselho, a sua dinâmica e suas deliberações podem fugir do seu controle e, portan- to, envolver custos políticos.

No caso do prestador, parece prevalecer o entendimento de que o CMSC não se constitui como uma arena relevante de ação política. Os prestadores percebem que, ao contrário do Conselho de Assistência Social e do Conselho da Criança e do Adolescente ${ }^{35}$, o CMSC não delibera, com freqüência, sobre assuntos de seu interesse. Com a ausência de motivação, os recursos não se convertem em influência política ${ }^{36}$.

Além disso, parece prevalecer entre os prestadores o entendimento de que as decisões reais são tomadas em outras arenas; ou seja, o Conselho não é percebido como um real espaço de tomada de decisão política na área de saúde. Do ponto de vista formal, a influência do CMSC no sistema político curitibano parece ser limitada, especialmente considerando: 1) a inexistência de uma clara definição jurídica quanto à sua atribuição deliberativa no campo da definição de políticas públicas ${ }^{37}$; 2) a inexistência de mecanismos

35 Nesses conselhos, os assuntos sobre os quais mais se decide são "credenciamento" e "finanças". O credenciamento refere-se à concessão ou renovação de autorização para que a entidade de assistência social possa, ao ser credenciada, pleitear acesso a recursos públicos para serem aplicados em suas atividades assistenciais. O tema "finanças" refere-se, com certa freqüência, a pedidos de auxílio aos fundos municipais que gerem recursos públicos da área social em questão. É importante salientar que tanto o credenciamento como a solicitação de recursos têm como beneficiários os prestadores de serviço da área em que o conselho atua.

36 Atuando prioritariamente como instância de fiscalização, a ação do conselho pode, eventualmente, prejudicar setores da sociedade representados pelos prestadores. Isso estimula mais a ação dos prestadores no sentido criar obstáculos às ações do conselho que de encaminhar propostas que atendam aos seus interesses.

37 As atribuições do Conselho não são definidas de maneira unívoca pelos diversos instrumentos jurídicos que o regulam. Alguns instrumentos jurídicos, como a lei que criou o Conselho Municipal de Saúde de Curitiba e a Conferência Municipal de Saúde de Curitiba (Lei Municipal n. 7 631, de 17 de abril de 1991), reforçam o caráter fiscalizador do Conselho, conferindo-lhe os meios necessários para que tal atividade possa ser desempenhada. Já outros, em especial o Regimento Interno do CMSC, ampliam, de maneira significativa, as suas atribuições, especialmente como espaço de definição das políticas públicas na área de saúde. Portanto, o caráter deliberativo do Conselho na definição da política pública de saúde está longe de ser bem estabelecido pela legislação. 
institucionalizados de controle social, por meio dos quais o CMSC possa impor sanções; 3) que as resoluções do CMSC têm de ser homologadas pelo poder Executivo, antes de serem publicadas como normas públicas e estatais.

Podemos supor, então, que os prestadores entendam que, considerando o baixo poder político do CMSC, não valha a pena investir em uma ação mais incisiva nessa arena. Por outro lado, o "projeto" de conferir maior centralidade ao Conselho enquanto instância definidora de políticas públicas e atuante no exercício do controle social pode servir como um poderoso estímulo para o ativismo dos usuários. Esse projeto, gerador de uma grande motivação para a ação política, pode estar associado à menor presença dos usuários em outras arenas, inclusive em função da sua maior fragilidade no que diz respeito à posse de recursos convencionais. É importante salientar que, devido ao caráter ambíguo e mesmo contraditório dos documentos legais, tal projeto (dos usuários) não deixa de ter fundamentos "reais". Tudo isso reflete uma luta em torno da forma (e do poder) que vai adquirir essa nova estrutura institucional envolvendo a participação política ampliada.

Fica, então, evidente que o estudo da influência política no interior de uma determinada arena pública é incompleto se não levar em conta o peso de tal instituição no sistema mais amplo de arenas públicas (HILGARTNER \& BOSK, 1988), assim como a percepção dos diversos atores envolvidos a respeito da importância de tal arena.

Além disso, vários outros fatores contribuem para explicar a ação e a influência política em arenas públicas envolvendo a participação ampliada, como é o caso do CMSC. Entre eles, destacamos o grau de heterogeneidade ideológica e de interesses em jogo entre os grupos que atuam na arena; o grau de coesão ${ }^{38}$ interna dos diferentes segmentos e das alianças entre eles; as características das áreas temáticas (MELLO, 2002) que predominam

38 Podemos supor, por exemplo, que o segmento que representa os usuários seja constituído por entidades heterogêneas e, muitas vezes, antagônicas entre si, formando um bloco menos unido do que os poucos prestadores de serviços ou membros da Administração. Além disso, devemos também considerar o perfil partidário-ideológico do poder Executivo. na agenda do conselho e a distribuição interna de cargos e direitos nos conselhos.

Ou seja, devemos considerar os fatores que configuram o contexto (interno ${ }^{39}$ e externo) em que os conselhos inserem-se. Esses contextos ${ }^{40}$ "estruturaram", em alguma medida, os distintos padrões de ação e interação no interior dos conselhos e explicam porque, em certa medida, recursos não se traduzem, automaticamente e em proporção direta, em participação, influência ou poder político.

O conjunto dessas considerações indica que a simples associação recursos-influência política não é suficiente para explicar a participação política no processo decisório dos conselhos. Fatores externos a esse modelo configuram o contexto da interação, delimitando o papel dos recursos no comportamento dos atores. Pensar a influência política exclusivamente em termos de recursos é reduzir a explicação de tal fenômeno a um formalismo incapaz de dar conta das circunstâncias reais em que as arenas estruturam-se e o processo decisório desdobra-se.

\section{CONSIDERAÇÕES FINAIS}

Não há dúvida de que as novas formas institucionais de participação política criadas e ampliadas a partir de 1988 contribuem no sentido do aumento de qualidade da experiência democrática no Brasil. A existência de instituições públicas mais permeáveis à influência da sociedade civil, conduzindo à entrada de novos atores nas arenas públicas institucionalizadas, é, certamente, saudável para a democracia.

39 Em relação ao contexto interno do conselho, um aspecto a ser considerado é o legado advindo da sua própria história: 1) ele foi estruturado de “cima para baixo” ou é apenas um momento de um processo mais abrangente, envolvendo a mobilização de segmentos organizados da sociedade civil? 2) Esse legado é constituído por um padrão de interação caracterizado por intensos conflitos ou por uma relativa harmonia entre os segmentos dos conselhos?

40 Embora o presente estudo aponte, claramente, os seus próprios limites, enquanto uma análise fundada, exclusivamente, em dados referentes à posse de recursos e à influência dos atores no processo decisório, ele não se propõe a proporcionar uma investigação mais abrangente. Essa ampla variedade de aspectos contextuais constituiu uma dimensão do processo decisório que, de acordo com as nossas conclusões, não deve ser ignorada em novas pesquisas. 
Mas a participação política não é um fenômeno que se explique apenas como decorrência da existência (ou não) de espaços institucionais adequados. Certamente, aspectos do desenho institucional do CMSC - em especial, o peso da representação dos usuários e as prerrogativas do gestor - exercem um papel importante no comportamento político dos segmentos. Todavia, em grande medida, o que o nosso estudo buscou mostrar é que a participação e a influência política dependem da distribuição de certas condições favoráveis para o seu exercício entre os diversos indivíduos e grupos, muitas das quais são externas à arena pública em foco.

Testamos, neste artigo, a hipótese de que a posse de determinados recursos explica a distribuição da participação no CMSC. Nossa conclusão indicou que, embora tenha-se revelado útil, o modelo fundado na posse de recursos mostrouse incapaz de fornecer uma compreensão plena e integrada da participação e influência política no CMSC. Entendemos, portanto, que outras condições devem ser consideradas na explicação da influência política. Além das condições favoráveis à ação política que não se enquadram na concepção convencional de "recursos", levamos em consideração a existência de um sistema de arenas públicas, no interior do qual os conselhos situamse. Entendemos, portanto, que a análise isolada de uma arena - especialmente se ela não for "central” - não revela o cenário mais amplo das ações estratégicas dos grupos.

Embora não tenham sido objeto de análise neste artigo, os fatores que configuram o contexto "interno" dos conselhos contribuem para a formação de distintos padrões de ação e interação e ajudam a explicar porque nem sempre os recursos traduzem-se em influência política, assim como as diferentes disposições para a ação dos diversos segmentos. Esse contexto define-se com a própria história do Conselho e a trajetória das forças sociais que atuam nele ${ }^{41}$. São também elementos formadores desse contexto o grau de heterogeneidade ideológica, o grau de heterogeneidade dos interesses em jogo, as características das áreas temáticas (MELLO, 2002), e a distribuição de direitos (como, por exemplo, a prerrogativa do gestor em presidir alguns conselhos ou homologar as suas resoluções) nos conselhos.

Quanto à distribuição da influência política no CMSC, o cenário é de dispersão. Embora haja um certo predomínio dos gestores no processo decisório do Conselho, prevalece uma dinâmica de equilíbrio político, especialmente devido ao papel ativo desempenhado pelos usuários nos debates e nas deliberações do CMSC. Com isso, pode-se afirmar que o Conselho Municipal de Saúde de Curitiba vem cumprindo, em grande medida, a aspiração de constituir-se em uma arena orientada pelo ideal da "participação ampliada”.

41 Uma questão crucial aqui é se e em que medida ele foi estruturado de "cima para baixo" ou é apenas um capítulo de um movimento mais abrangente, envolvendo a mobilização de segmentos, mais ou menos amplos, mais ou menos organizados, da sociedade civil.

Mário Fuks (mariofuks@uol.com.br) é Doutor em Ciência Política pelo Instituto Universitário de Pesquisas do Rio de Janeiro (Iuperj) e Professor do Departamento de Ciência Política da Universidade Federal de Minas Gerais (UFMG).

\section{REFERÊNCIAS BIBLIOGRÁFICAS}

ALMOND, G. \& VERBA, S. 1989. The Civic Culture : Political Attitudes and Democracy in Five Nations. New York : Sage.

ARRETCHE, M. 1999. Políticas sociais no Brasil : descentralização em um Estado federativo. Revista Brasileira de Ciências Sociais, São Paulo, v. 14, n. 40, p. 111-141, jun.
BOBBIO, N. 1994. Liberalismo e democracia. São Paulo : Brasiliense

CARVALHO, A. I. 1997. Conselho de Saúde, responsabilidade pública e cidadania : a reforma sanitária como reforma do Estado. In : FLEURY, S. (org.). Saúde e democracia : a luta do CEBES. São Paulo : Lemos. 
COBB, R. W. \& ROSS, M. H. (eds.). 1997. Cultural Strategies of Agenda Denial : Avoidance, Attack, and Redefinition. Kansas : Kansas University.

CÔRTES, S. M. V. 1998. Conselhos Municipais de Saúde : a possibilidade de os usuários participarem e os determinantes da participação. Ciência e Saúde Coletiva, Rio de Janeiro, v. III, n. 1, p. 6-17.

GOHN, M. G. 2001. Conselhos gestores e participação sociopolítica. São Paulo : Cortez.

HILGARTNER, S. \& BOSK, C. L. 1988. The Rise and Fall of Social Problems : A Public Arenas Model. American Journal of Sociology, Chicago, v. 94, n. 1, p. 53-78, July.

FUKS, M. 2002. Participação política em conselhos gestores de políticas sociais no Paraná. In : PERISSINOTTO, R. M. \& FUKS, M. (orgs.). Democracia : teoria e prática. Rio de Janeiro : Relume-Dumará.

FUKS, M.; PERISSINOTO, R. M. \& RIBEIRO, E. A. 2003. Cultura política e desigualdade : o caso dos conselhos municipais de Curitiba. Revista de Sociologia e Política, Curitiba, n. 21, p. 125-145, nov.
MARSCHALL, M. 2000. The Institutional and Social Contexts of Participation : American Inner Cities. Trabalho apresentado no encontro anual do European Consortium for Political Research, em Copenhague (Dinamarca). Digit.

MELLO, M. A. 2002. Reformas constitucionais no Brasil : instituições políticas e processo decisório. Rio de Janeiro : Revan.

PATEMAN, C. 1992. Participação e teoria democrática. Rio de Janeiro : Paz e Terra.

SCHLOZMAN, K.; VERBA, S. \& BRADY, H. 1999. Civic Participation and the Equality Problem. In : SKOCPOL, T. \& FIORINA, M. (eds.). Civic Engagement in American Democracy. Washington, D. C. : The Brookings Institution.

SKOCPOL, T. \& FIORINA, M. 1999. Making Sense of the Civic Engagement Debate. In : SKOCPOL, T. \& FIORINA, M. (eds.). Civic Engagement in American Democracy. Washington, D. C. : The Brookings Institution.

ZALLER, J. 1992. The Nature and Origins of Mass Opinion. Cambrige : Cambrige University.

\section{OUTRAS FONTES}

NÚCLEO DE PESQUISA “DEMOCRACIA E INSTITUIÇÕES POLÍTICAS PARANAEN-

SES". s/d. Pesquisa "Democracia e políticas sociais no Paraná”. Curitiba : Universidade Federal do Paraná. 